\title{
The impact of LEEP margin status on subsequent abnormal cervical cytology
}

\author{
Andrea S O'Shea, MD, ${ }^{1}$ Colleen $\mathrm{K}$ Stockdale, MD, $\mathrm{MS}^{1}$ \\ Keywords: cervical intraepithelial neoplasia/pathology, cervical intraepithelial neoplasia/surgery, \\ electrosurgery, LEEP, loop electrosurgical excision procedure, cytology, Pap smear
}

\begin{abstract}
Objective: To evaluate the relationship between Loop Electrosurgical Excision Procedure (LEEP) margin status and subsequent cytology results to determine the significance of margin status as a predictor for recurrent cervical disease.

Methods: A retrospective cohort of women who underwent LEEP for treatment of cervical dysplasia from 1995 to 2006 with subsequent follow-up to 2009 at a single academic institution. Data extracted consisted of information routinely collected during clinic visits including demographic information, LEEP histology results, and cytology results.
\end{abstract}

Results: The analysis was limited to 144 women with documented LEEP margin status and subsequent cytologic follow-up. The women were predominantly white, non-Hispanic, with a mean age of 27 years (range $14-62$ years). Of the 144 LEEP specimens, 77 had negative margins, and 67 had positive margins (44 ectocervical, 16 endo-cervical, 7 both ecto-cervical and endo-cervical margins involved). Twentythree women required subsequent colposcopy during the follow-up period: 7 with negative margin status and 16 with positive margin status on their initial LEEP. There was no association between LEEP margin status, grade of dysplasia, or depth of excision, and subsequent abnormal cytology ( $P>0.05$ for each). There was no association between positive ecto-cervical or endo-cervical margin status and subsequent abnormal cytology ( $P>0.05$ for each).

Conclusion: We were unable to identify factors related to $L E E P$ margin status to predict recurrent abnormal cytology. Thus, we recommend surveillance of all women following LEEP for cervical dysplasia regardless of margin status.

${ }^{1}$ University of lowa Hospitals and Clinics, Department of Obstetrics and Gynecology, lowa City, lowa.

\section{Objective}

The aim of this study was to evaluate the relationship between LEEP margin status and subsequent cytology results to determine the significance of margin status as a predictor for recurrent cervical disease.

Please cite this paper as: O'Shea AS, Stockdale CK. The impact of LEEP margin status on subsequent abnormal cervical cytology. Proc Obstet Gynecol. 2014;4(2): Article 5 [ 8 p.]. Available from: http://ir.uiowa.edu/pog/. Free full text article.

Corresponding author: Colleen K Stockdale, MD, MS, University of lowa Hospitals and Clinics, Department of Obstetrics \& Gynecology, 51214 PFP, 200 Hawkins Drive, lowa City, IA 52242-3225. Phone: 319-384-6849. FAX: 319-384-8620. colleen-stockdale@uiowa.edu

Copyright: (c) 2014 O'Shea, Stockdale. This is an open-access article distributed under the terms of the Creative Commons Attribution License, which permits unrestricted use, distribution, and reproduction in any medium, provided the original author and source are credited. 


\section{Background}

Over the past two decades, data has emerged regarding the natural history of cervical intraepithelial neoplasia $(\mathrm{CIN})$ in various age groups. Concomitant evidence showing obstetrical risk following treatment for $\mathrm{CIN}$ has led to the re-evaluation of guidelines for the management of abnormal cervical cancer screening tests and premalignant cervical disease with a trend towards conservative management. ${ }^{1}$ However, surgical therapies remain the mainstay of treatment for high grade cervical intraepithelial neoplasia (CIN 2,3). Loop electrosurgical excision procedure (LEEP) is a commonly utilized diagnostic and treatment modality for CIN 2,3 because it provides a specimen for histological examination while being safe and effective in the outpatient setting. ${ }^{2}$ In select patients, it also has the advantage of allowing diagnosis and treatment in a single visit. ${ }^{2}$ Treatment is not without risk, however. As stated above, increased obstetrical risks following treatment with LEEP include preterm premature rupture of membranes, preterm delivery, and low birth weight. ${ }^{3-5}$ Such risks highlight the trend for more conservative management of CIN 2 and $\mathrm{CIN} 2,3$ especially in younger populations.

Women who have undergone treatment for CIN 2,3 are also at risk for persistent or recurrent disease, with rates of disease persistence/recurrence ranging from 2-48\% following LEEP., 4 ,6-8 Such women are also at increased risk for developing invasive cervical cancer for as many as 20 years following treatment, further highlighting the need for follow-up in these patients. ${ }^{9}$ Various follow-up schedules have been proposed, but data regarding the most effective follow-up schedule for detecting disease persistence or recurrence is lacking. It is also unclear whether women with incomplete excision by LEEP, as evidenced by the histologic presence of $\mathrm{CIN}$ at the margin of the excised specimen, are at an increased risk of disease persistence or recurrence. For such women, the most recent consensus guidelines from the American Society for Colposcopy and Cervical Pathology (ASCCP) preferentially recommend follow-up with cytology and endocervical sampling over re-excision; however, repeat excision is acceptable. ${ }^{1}$ Nonetheless, uncertainty remains as to whether immediate re-excision or close clinical follow-up is the best course of action. This study seeks to add to the growing body of literature regarding the significance of positive margin status following LEEP as it relates to the patient's risk for future abnormal cervical cytology.

\section{Methods}

This represents a retrospective cohort study of women who underwent LEEP for cervical dysplasia at a single academic institution from 1995 to 2006 with follow-up to 2009. The protocol for the study was approved by the Institutional Review Board. All women who underwent a LEEP procedure for cervical dysplasia with known margin status and who had subsequent 
cytological follow up were eligible for analysis.

Data extracted consisted of information routinely collected during clinic visits including demographic information, cytology results, and LEEP histology results. LEEP specimen margin status was analyzed with regards to residual disease (positive, negative), margin involved (ectocervical, endocervical), and grade of dysplasia present at the margin. The grade of dysplasia at the margin was stratified as normal (normal, inflammation, CIN 1) or abnormal (CIN 2, CIN 3, adenocarcinoma in-situ, microinvasive cancer, invasive cancer). Pap smear results of atypical squamous cells (ASC) and low grade intraepithelial lesions (LSIL) were classified as mild; atypical squamous cells, cannot exclude high grade (ASC-H), high grade intraepithelial lesions (HSIL), and atypical glandular cells (AGC) were classified as severe. For patients with multiple post-LEEP cytology results, the most abnormal result was used in the analysis.

Data was analyzed by univariate analysis using Fisher's exact test to determine whether LEEP specimen margin status was correlated with subsequent cytology results. For continuous variables, Wilcoxon rank sum test was applied to examine the correlation between depth of excision and subsequent cervical cytology.

For variables with ample data, multivariate analysis with logistic regression using stepwise selection was used. Because of limited sample size, for multivariate analysis, subsequent Pap smear results were re-categorized with non-clinically significant disease classified as normal (ASC, LSIL) and clinically significant disease classified as abnormal (ASC-H, HSIL, AGC). Covariates included age, current smoking status, gravidity, parity, contraceptive use, history of gynecologic disease, and result of the most recent colposcopy prior to the treatment of interest.

\section{Results}

Two hundred and twenty-eight women were identified who underwent LEEP for treatment of high grade cervical dysplasia at our institution from 1995 to 2006. Follow-up cytology was available for 167 of the women. The analysis was limited to 144 women for whom both documented LEEP margin status and cytological follow-up data were available.

The women were predominantly white, non-Hispanic, with a mean age of 27 years (range 14-62). Demographics for the women who underwent LEEP are presented (Table 1).

Similar to other reviews, current smoking status was associated with referral for treatment of cervical dysplasia (LEEP) $(p=0.04)$. Use of hormonal birth control (primarily combined oral contraceptives) approached significance for referral for treatment $\quad(p=0.06)$. Demographic variables were not associated with follow-up cytology results on univariate or multivariate analyses. 
Table 1. Demographics of all LEEP patients $(n=228)$

\begin{tabular}{|l|c|c|}
\hline \multicolumn{1}{|c|}{ Age } & (years) & p-value \\
\hline Range & $14-62$ & ns \\
\hline Mean & 27 & \\
\hline \multicolumn{1}{|c|}{ OB history } & Number (\%) & ns \\
\hline Nulligravida & $61(27)$ & \\
\hline Previous pregnancy & $162(71)$ & \\
\hline Missing information & $5(2)$ & \\
\hline \multicolumn{1}{|c|}{ Smoking status } & Number (\%) & 0.04 \\
\hline Non-smoker & $113(50)$ & \\
\hline Current smoker & $109(48)$ & \\
\hline Missing information & $6(2)$ & \\
\hline \multicolumn{1}{|c|}{ Birth control } & Number (\%) & 0.06 \\
\hline Yes & $137(60)$ & \\
\hline No & $90(39)$ & \\
\hline Missing information & $1(0)$ & \\
\hline
\end{tabular}

The LEEP pathology reported positive margin status in $67(47 \%)$ of the specimens and negative margin status in 77 (53\%). For those specimens with a positive margin status where the involved margin was specified, the ectocervical margin was positive in 51 specimens and the endocervical margin was positive in 23 (this includes 7 specimens in which both the ecto- and endo-cervical margins were involved). The frequency of subsequent Pap smear results by margin status is presented in Table 2.

Table 2. Frequency of subsequent Pap smear results by margin status $(n=144)$

\begin{tabular}{|c|c|c|c|c|}
\hline & \multicolumn{3}{|c|}{ Follow-up Pap smear result } & \multirow{2}{*}{ p-value } \\
\hline & Normal & Mild & Severe & \\
\hline \multicolumn{5}{|l|}{ LEEP margin status } \\
\hline Positive & 33 & 24 & 10 & \multirow{2}{*}{0.56} \\
\hline Negative & 40 & 30 & 7 & \\
\hline \multicolumn{5}{|l|}{ Endocervical margin } \\
\hline Positive & 8 & 10 & 5 & \multirow{2}{*}{0.13} \\
\hline Negative & 24 & 13 & 5 & \\
\hline \multicolumn{5}{|l|}{ Ectocervical margin } \\
\hline Positive & 27 & 18 & 6 & \multirow{2}{*}{0.25} \\
\hline Negative & 5 & 5 & 4 & \\
\hline \multicolumn{5}{|l|}{ Margin Grade } \\
\hline Normal/Low $(\leq \mathrm{CIN} I)$ & 19 & 9 & 4 & \multirow{2}{*}{0.30} \\
\hline Moderate/High ( $\geq$ CIN II) & 13 & 15 & 5 & \\
\hline \multicolumn{5}{|l|}{ Margin Depth } \\
\hline Mean (mm) & 11.12 & 10.78 & 9.73 & 0.15 \\
\hline
\end{tabular}


In those with a positive LEEP margin, post-LEEP cytology results were normal in 33 women, mild in 24, and severe in 10. In those with a negative LEEP margin, post-LEEP cytology results were normal in 40 , mild in 30 , and severe in 7 . There was no correlation between follow-up cytology result and positive or negative margin status $(p=0.56)$. Likewise there was no correlation between follow-up cytology result and margin involved (endo- or ecto-cervical) $(p=0.13)$ or grade of dysplasia identified at the margin ( $p$ $=0.30$ )

The mean depth of excision was 11.12 $\mathrm{mm}$ in those with normal cytology postLEEP, $10.78 \mathrm{~mm}$ in those with a mild result, and $9.73 \mathrm{~mm}$ in those with a severe result. Using Wilcoxon rank sum test, there was no significant difference noted between mean depth of excision and follow-up cytology result $(p=0.15)$.

Twenty-three women required subsequent colposcopy during the follow-up period: 7 with negative margin status and 16 with a positive margin status on their initial LEEP. The result of the follow-up colposcopy was not found to be significantly different based upon initial margin status $(p=0.19)$, grade of dysplasia at the margin $(p=0.33)$, or depth of excision ( $p=0.82)$. Additionally, multivariate analysis using the covariates listed above found no significant factors. However, when the sample was restricted to women who had a positive margin at initial treatment, the margin depth approached significance $(p=0.06)$.

\section{Discussion}

The present study sought to evaluate the significance of a positive margin following treatment with LEEP as it relates to risk for future abnormal cytology. Although guidelines for the management of such patients exist, there is little data or consensus on whether these patients should be followed clinically or undergo reexcision. Furthermore, no data exists regarding adherence to the present recommendations following treatment. In an attempt to determine the best course of action for such patients, many studies, including this one, have looked at risk factors for recurrence of cervical dysplasia to determine those patients for whom the risk of disease recurrence outweighs the risks of re-excision. While re-excision in patients with a positive margin is well tolerated and effective, ${ }^{6,10}$ there are risks associated with reexcision. Risks of repeat excision must be weighed against the potential risk of untreated CIN or the potential for a missed diagnosis of invasive carcinoma within an un-excised focus at the involved margin. This has become especially important in light of recent data showing increased obstetrical risks following LEEP and the desire to therefore limit cervical excision in women desiring future fertility. ${ }^{3-5}$

In the present study, we were unable to identify risk factors to predict recurrent abnormal cytology related to LEEP margin status. Previous studies have reported conflicting results, with many studies showing a statistically higher rate of disease recurrence (as 
determined by follow-up cytology) in those with a positive LEEP resection margin., ${ }^{8,11-17}$ Margin status was compared in several studies, again with conflicting results: statistically higher rate of persistence/recurrence was seen only in those patients with involvement of the ectocervical margin ${ }^{17}$ or endocervical margin ${ }^{7,12,16}$ or only with extensive involvement of the margin. ${ }^{13}$

Limitations of our study include the small sample size. This is largely a reflection of the referral population base and study methods. The majority of women who are referred to the University for evaluation of abnormal cervical cytology and treatment of cervical dysplasia are cared for by practitioners from a wide geographical area and tend to receive follow up care with their referring providers Thus, we do not have available post-LEEP cytology for all women. Another limitation was the transition of our clinic records from a paper record to an electronic medical record during the study period. Thus, some women who underwent LEEP did not have all the required information and were excluded. While our findings are limited, it is unlikely that our findings have been biased by the referral population or methods available. Our findings are similar to other studies in that noninvasive LEEP histology is a poor predictor of recurrent $\mathrm{CIN}$ following LEEP.

In conclusion, we were unable to identify which women are at risk for a recurrence of CIN following LEEP based on margin status. Thus, we recommend surveillance of all women who have undergone LEEP for treatment of CIN regardless of margin status.

\section{References}

1. Massad LS, Einstein MH, Huh WK, Katki HA, Kinney WK, Schiffman M, Solomon $\mathrm{D}$, Wentzensen $\mathrm{N}$, Lawson HW; 2012 ASCCP Consensus Guidelines Conference. 2012 updated consensus guidelines for the management of abnormal cervical cancer screening tests and cancer precursors. J Low Genit Tract Dis. 2013 Apr;17(5 Suppl 1):S1-S27. doi: 10.1097/LGT.0b013e318287d329.

Erratum in: J Low Genit Tract Dis. 2013 Jul;17(3):367. PubMed PMID: 23519301.

2. Wright TC Jr, Gagnon S, Richart RM, Ferenczy A. Treatment of cervical intraepithelial neoplasia using the loop electrosurgical excision procedure. Obstet Gynecol. 1992 Feb;79(2):173-8. PubMed PMID: 1731281.

3. Kyrgiou M, Koliopoulos G, Martin-Hirsch $P$, Arbyn $M$, Prendiville $W$, Paraskevaidis E. Obstetric outcomes after conservative treatment for intraepithelial or early invasive cervical lesions: systematic review and metaanalysis. Lancet. $2006 \quad$ Feb 11;367(9509):489-98. DOI: 10.1016/S0140-6736(06)68181-6.

PubMed PMID:16473126.

4. Sadler L, Saftlas A, Wang W, Exeter M, Whittaker J, McCowan L. Treatment for cervical intraepithelial neoplasia and risk of preterm delivery. JAMA. 2004 May 5;291(17):2100-6. http://dx.doi.org/10.1001/jama.291.17.21 00. PubMed PMID: 15126438. 
5. Samson SL, Bentley JR, Fahey TJ, McKay DJ, Gill GH. The effect of loop electrosurgical excision procedure on future pregnancy outcome. Obstet Gynecol. $2005 \quad$ Feb;105(2):325-32. http://dx.doi.org/10.1097/01.AOG.00001 51991.09124.bb. PubMed PMID: 15684160.

6. Brockmeyer $A D$, Wright JD, Gao $F$, Powell MA. Persistent and recurrent cervical dysplasia after loop electrosurgical excision procedure. Am J Obstet Gynecol. 2005 May;192(5):137981.

http://dx.doi.org/10.1016/j.ajog.2004.12. 044. PubMed PMID: 15902114.

7. Costa S, De Nuzzo M, Infante FE, Bonavita B, Marinelli M, Rubino A, Rambelli V, Santini D, Cristiani P, Bucchi L. Disease persistence in patients with cervical intraepithelial neoplasia undergoing electrosurgical conization. Gynecol Oncol. 2002 Apr;85(1):119-24. DOI: 10.1006/gyno.2001.6579. PubMed PMID: 11925130.

8. Dobbs SP, Asmussen $\mathrm{T}$, Nunns $\mathrm{D}$, Hollingworth J, Brown LJ, Ireland D. Does histological incomplete excision of cervical intraepithelial neoplasia following large loop excision of transformation zone increase recurrence rates? A six year cytological follow up. BJOG. 2000 Oct;107(10):1298-301. http://dx.doi.org/10.1111/j.1471-

0528.2000.tb11623.x. PubMed PMID: 11028584.

9. Soutter WP, Sasieni $P$, Panoskaltsis $T$. Long-term risk of invasive cervical cancer after treatment of squamous cervical intraepithelial neoplasia. Int J Cancer. 2006 Apr 15;118(8):2048-55. DOI: 10.1002/ijc.21604. PubMed PMID: 16284947.
10. Siriaree S, Srisomboon J, Kietpeerakool C, Khunamornpong S, Siriaunkgul S, Natpratan A, Pratheapjarus S, Futemwong $A$, Chantarasenawong $U$. High-grade squamous intraepithelial lesion with endocervical cone margin involvement after cervical loop electrosurgical excision: what should a clinician do? Asian Pac J Cancer Prev. 2006 Jul-Sep;7(3):463-6. PubMed PMID: 17059346.

11. Lu CH, Liu FS, Kuo CJ, Chang CC, Ho ES. Prediction of persistence or recurrence after conization for cervical intraepithelial neoplasia III. Obstet Gynecol. 2006 Apr;107(4):830-5. http://dx.doi.org/10.1097/01.AOG.00002 06777.28541.fc. PubMed PMID: 16582119.

12. Felix JC, Muderspach LI, Duggan BD, Roman LD. The significance of positive margins in loop electrosurgical cone biopsies. Obstet Gynecol. 1994 Dec;84(6):996-1000. PubMed PMID: 7970484.

13. Kietpeerakool C, Khunamornpong S, Srisomboon J, Siriaunkgul S, Suprasert P. Cervical intraepithelial neoplasia II-III with endocervical cone margin involvement after cervical loop conization: is there any predictor for residual disease? J Obstet Gynaecol Res. $2007 \quad$ Oct;33(5):660-4. http://dx.doi.org/10.1111/j.1447-

0756.2007.00628.x. PubMed PMID: 17845326 .

14. Lubrano A, Medina N, Benito $V$, Arencibia O, Falcón JM, Leon L, Molina J, Falcón O. Follow-up after LLETZ: a study of 682 cases of CIN 2-CIN 3 in a single institution. Eur J Obstet Gynecol Reprod Biol. 2012 Mar;161(1):71-4. doi:10.1016/j.ejogrb.2011.11.023. Epub 2011 Dec 15. PubMed PMID: 22177836. 
15. Malapati R, Chaparala S, Cejtin HE. Factors influencing persistence or recurrence of cervical intraepithelial neoplasia after loop electrosurgical excision procedure. J Low Genit Tract Dis. $2011 \quad$ Jul;15(3):177-9. doi:10.1097/LGT.0b013e3181fee61d. PubMed PMID: 21716049.

16. Rodolakis A, Thomakos N, Haidopoulos $D$, Antsaklis A. Management of relapsing cervical intraepithelial neoplasia. J Reprod Med. 2009 Aug;54(8):499-505. PubMed PMID: 19769196.
17. Sandweiss L, Thompson A, Natarajan S. Cervical LEEP margin status and post-LEEP Pap smear follow-up. Int J Gynaecol Obstet. 2008 Mar;100(3):2845. Epub $2007 \quad \mathrm{Dec} 3$. http://dx.doi.org/10.1016/j.ijgo.2007.09.0 17. PubMed PMID: 18048042. 